\title{
Pharmacist intervention program to enhance hypertension control: a randomised controlled trial
}

\author{
Manuel Morgado • Sandra Rolo • \\ Miguel Castelo-Branco
}

Received: 17 July 2010/Accepted: 7 December 2010/Published online: 13 January 2011

(C) The Author(s) 2010. This article is published with open access at Springerlink.com

\begin{abstract}
Objective Studies have demonstrated that hypertension remains inadequately managed throughout the world, with lack of adherence to BP-lowering medication being a major factor. The aim of the present study was to evaluate if a pharmaceutical care program could improve antihypertensive medication adherence and blood pressure control. Setting This study was conducted in a secondary care hypertension/dyslipidemia outpatient clinic in the university teaching hospital of Cova da Beira Hospital Centre, Covilhã, located in the Eastern Central Region of Portugal. Method This report evaluates the pharmacist's interventions during a prospective randomised controlled trial, from July 2009 to June 2010. Patients with diagnosis of essential hypertension attending the clinic for routine follow-up were randomly allocated either to a control group (no pharmaceutical care) or to an intervention group (quarterly follow-up by a hospital pharmacist during a 9month period). The pharmacist interventions, aimed to increase medication adherence and blood pressure control, involved educational interventions and counselling tips directed to the patient. Main outcome measure Systolic blood pressure, diastolic blood pressure and blood pressure control (according to JNC 7 guidelines) assessed at the baseline visit and at the end of pharmaceutical care were the main outcome measures. Blood pressure measurements
\end{abstract}

M. Morgado $(\bowtie) \cdot$ M. Castelo-Branco

Health Sciences Research Centre, University of Beira Interior, Av. Infante D. Henrique, 6200-506 Covilhã, Portugal

e-mail: manuelaugustomorgado@gmail.com

URL: www.fcsaude.ubi.pt

M. Morgado · S. Rolo $\cdot$ M. Castelo-Branco

Hospital Centre of Cova da Beira, E.P.E., Quinta do Alvito, 6200-251 Covilhã, Portugal were performed by blinded nurses. Medication adherence was also evaluated, using a validated questionnaire at baseline and at the end of investigation. Results A total of 197 hypertensive patients were randomly assigned to the study (99 in the control group and 98 in the intervention group). Although there were no significant differences $(P>0.05)$ in both groups concerning mean age, gender, body mass index, and antihypertensive pharmacotherapy, blood pressure control was higher in the intervention group $(P=0.005)$ at the end of the study. Significant lower systolic blood pressure $(-6.8 \mathrm{mmHg}, P=0.006)$ and diastolic blood pressure $(-2.9 \mathrm{mmHg}, P=0.020)$ levels were observed in the intervention group. Medication adherence was also significantly higher in the intervention group at the end of the study $(74.5 \%$ vs. $57.6 \%$, $P=0.012)$.Conclusion Pharmacist intervention can significantly improve medication adherence and blood pressure control in patients treated with antihypertensive agents.

Keywords Blood pressure - Clinical trial $\cdot$ Hospital pharmacist - Hypertension - Medication adherence · Pharmaceutical care $\cdot$ Pharmacist intervention · Portugal

\section{Impact of findings on practice}

- Clinical hospital pharmacists can complement physicians in the management of hypertensive patients.

- Pharmacist interventions are effective in improving antihypertensive medication adherence and reducing systolic and diastolic blood pressure.

- Clinical pharmacists can effectively participate in health education and promotion to improve blood pressure control. 


\section{Introduction}

Hypertension is a major risk factor in the development of cardiovascular disease and an important public health problem worldwide. It is estimated that over three million Portuguese adults (about 30\% of the Portuguese population) suffer from hypertension. In a recently published survey [1] only $11.2 \%$ hypertensives had their blood pressure (BP) controlled. This figure is even lower in the Central Region of Portugal, where only $9.7 \%$ of the total number of hypertensives have their BP controlled [1]. Although the treatment of hypertension has been shown to prevent cardiovascular disease and to extend and enhance life [2, 3], hypertension remains inadequately managed throughout the world, with lack of adherence to BP-lowering medication being a major factor [4-7]. Hypertensive patients may fail to take their medication because of the symptomless nature of the condition, the long duration of therapy, side effects of medication, complicated drug regimens, lack of understanding about hypertension management and risks, and costs of medication [8, 9]. Antihypertensive medication adherence rates have differed widely depending on the population studied and it is estimated to range between 50 and $70 \%[6,10,11]$.

The importance of improving adherence to antihypertensive medication has been addressed by "The seventh report of the Joint National Committee on prevention, detection, evaluation and treatment of high BP" (JNC 7) [2] and emphasis has been put on the role of all health care professionals to improve adherence to treatment [2]. Previous studies have shown that introducing pharmaceutical care to hypertensive patients in community pharmacies improved medication adherence and patient outcomes [12-16]. However, this type of care for hypertensive outpatients in a hospital setting, where collaboration between physician and pharmacist is more feasible, has not previously been undertaken in Portugal and the study presented here is unique in this respect.

\section{Aim of the study}

The objectives of the present study were to evaluate the hospital clinic pharmacist's interventions during a prospective randomised controlled clinical trial (RCT), aimed to improve antihypertensive medication adherence and $\mathrm{BP}$ control in hypertensive patients in the ambulatory secondary care setting.

\section{Method}

This was a RCT, with participants individually randomised to one of two parallel groups (allocation ratio 1:1). Eligible participants were all adults aged 18 or over with an established medical diagnosis of arterial hypertension, whether their BP was controlled or not. According to the JNC 7 guidelines, BP control was defined as BP measurements in the clinic of systolic $\mathrm{BP}(\mathrm{SBP})<140 \mathrm{mmHg}$ and diastolic BP (DBP) $<90 \mathrm{mmHg}$ for patients without diabetes or chronic kidney disease (CKD) and of SBP $<130 \mathrm{mmHg}$ and DBP $<80 \mathrm{mmHg}$ for patients with diabetes or CKD. Furthermore, all included patients had been on established antihypertensive drug treatment for at least 6 months. Exclusion criteria were dementia, pregnancy and breastfeeding. The study was carried out from July 2009 to June 2010 in a hypertension/dyslipidemia clinic in the university hospital of Cova da Beira Hospital Centre, Covilhã, located in the Eastern Central Region of Portugal. The study was approved by the institutional Ethics Committee for the use of humans in research, and written informed consent was obtained from all participants before their enrollment in the study.

Outpatients attending the medical clinic for routine follow-up were randomly allocated either to a control group $[(\mathrm{CG})$ usual care, where no pharmaceutical care is provided] or to an intervention group [(IG) pharmaceutical care, consisting of quarterly follow-up by a hospital clinical pharmacist during a 9-month period]. Participants were allocated following simple randomisation procedures (equal allocation and without restrictions) using a computer-generated list of random numbers. The allocation sequence was concealed from the clinical pharmacist enrolling and assessing participants in sequentially numbered, opaque, sealed envelopes. The computer generated the allocation sequence and the envelopes were prepared by a researcher with no clinical involvement in the trial. Based on the nature of the intervention, it is not feasible to blind hypertensive patients in pharmaceutical intervention models. Thus, whereas patients, pharmacists and physicians were aware of the patient allocated arm, nurses assessing BP were kept blinded to the allocation.

The pharmaceutical care provided to the IG by a clinical pharmacist consisted in the baseline visit (lasting approximately $30 \mathrm{~min}$ ) and the follow-up visits (lasting approximately $20 \mathrm{~min}$ ) conducted with each intervention patient at 3 and 6 months. The clinical pharmacist could also schedule additional optional visits between scheduled visits at his discretion. At each visit, the clinical pharmacist conducted a thorough interview of the patient, identified problems leading to poor BP control, provided patient education (hypertension education, BP self-monitoring recommendation, goal BP to achieve, lifestyle education and counselling, medication education and counselling tips to enhance adherence), and presented recommendations to the physician regarding changes in drug therapy. The recommended lifestyle changes for BP control were in accordance with the JNC 7 guidelines [2]. Patients in the IG were also provided 
with written educational material about hypertension and possible complications, as well as healthy lifestyle practices. Furthermore intervention patients were encouraged to bring all empty blisters and boxes of antihypertensive medication to clinic visits for recycling and to verify compliance to therapy. The CG had no clinical pharmacist involvement and control patients received the traditional service provided by the hospital clinic.

The primary outcome measures with respect to pharmaceutical care efficacy were the proportion of patients achieving BP control and reduction in baseline SBP and DBP. The BP clinic measurement was performed by trained nurses blind to the study, according to the published guidelines on proper BP measurement issued by the Portuguese Society of Hipertension [17]. Validated automatic BP measuring devices (Omron M4-I, validated by the British Society of hypertension [18]) and appropriate cuffs were used, the mean of two consecutive measurements being recorded. The secondary outcome measure was antihypertensive medication adherence, which was determined in both arms by a pharmacist using a validated five-item adherence scale [19, 20], derived from the four-item scale developed by Morisky et al. [21, 22]. Low medication adherence was defined as answering yes to 3 or more of 5 questions [23]. Patient knowledge of target BP values and of hypertension risks were also evaluated. Patients were considered knowledgeable of target BP values if they knew both target BP figures $(<140 /<90 \mathrm{mmHg}$ for hypertensive patients without diabetes and CKD and $<130 /<80 \mathrm{mmHg}$ for hypertensive patients with diabetes or CKD). They were considered knowledgeable of the negative impacts of hypertension to health if they mentioned at least two potential major negative consequences of uncontrolled hypertension to health. SBP and DBP levels, BP control, medication adherence, patient knowledge of target BP values and of hypertension risks of both groups were assessed and compared at baseline and at the end of a 9-month period. In the final study visit (9-month) the IG did not receive pharmaceutical care and both arms had BP measured by a research nurse, and had medication adherence assessed by a pharmacist. If a subject failed to attend the exit visit despite multiple contact attempts (i.e., drop out), the last available clinic BP was extracted for intention-to-treat (ITT) analysis.

Clinical data for this study, including BP measures, medications prescribed and medical problems were prospectively obtained from the hospital electronic medical records (HEMR) database. The HEMR database is comprised of detailed patient-level clinical and administrative information from all patients that have used the hospital at least once. This database is authorized by the Portuguese government and patient data confidentiality was ensured.

To detect a reduction in SBP of $8-10 \mathrm{mmHg}$ [standard deviation (SD) 16-18 $\mathrm{mmHg}$ ], which is in agreement with several studies, with a two-sided $5 \%$ significance level and a power of $80 \%$, a sample size of 90 patients per group (180 total) was necessary, given an anticipated dropout rate of $10 \%$. To recruit this number of patients a 3-month (JulySeptember 2009) inclusion period was anticipated.

Demographic variables, clinical data, medication adherence and BP values of patients included in the study, as well as prescribing metrics were examined on a descriptive basis and expressed as the mean $\pm \mathrm{SD}$, frequency and percentages. Student's test and Mann-Whitney rank sum test were used to compare continuous variables and $\chi^{2}$ test and Fisher exact probability test were used to test for differences between categorical variables. All statistical analyses were done using SPSS for Windows, version 17.0 (SPSS Inc., Chicago, IL) and a $P$-value $<0.05$ was considered to indicate statistical significance.

\section{Results}

A total of 222 patients attended the medical clinic during the recruitment period (from July 2009 to September 2009) and all were assessed for eligibility. Of these, 17 were excluded from the study because they did not meet the inclusion criteria, 1 was excluded because of breastfeeding and 7 were excluded because they declined to participate. Of the 197 hypertensive patients meeting the inclusion criteria and consenting to participate, 99 were allocated to usual care (CG) and 98 were allocated to pharmaceutical care (IG) (Fig. 1).

The IG and CG were comparable with respect to age, gender, education, marital status, body mass index, smoking status, prevalence of chronic illness, number of antihypertensive drugs per patient, and number of years in antihypertensive treatment (Table 1).

The percentage of patients on angiotensin II receptor antagonists was the only significant difference detected between the two groups at baseline (Table 2).

Baseline SBP and DBP, BP control, stage 1 and stage 2 hypertension and medication adherence did not significantly differ in both groups either (Table 3 ).

As seen in Fig. 1, a total of 7 subjects $(3.6 \%)$ withdrew from the study following allocation, 4 (2.0\%) from the intervention arm and $3(1.5 \%)$ from the control arm. In the IG, 95 completed the 3-month visit, and 94 completed the 6-month as well as the final study visit. The clinical pharmacist scheduled a mean \pm SD of $0.6 \pm 0.6$ additional visits per patient in the IG, involving a total of 51 patients (7 patients had 2 additional visits).

At the beginning of the study, only 30 of $98(30.6 \%)$ patients in the IG had both SBP and DBP controlled. This was not significantly different from the number in the CG, where 35 of $99(35.4 \%)$ patients had their BP 
Fig. 1 Flow diagram of patients through the study protocol (according to CONSORT 2010 Statement). $B P$ blood pressure, $D B P$ diastolic blood pressure, $S B P$ systolic blood pressure

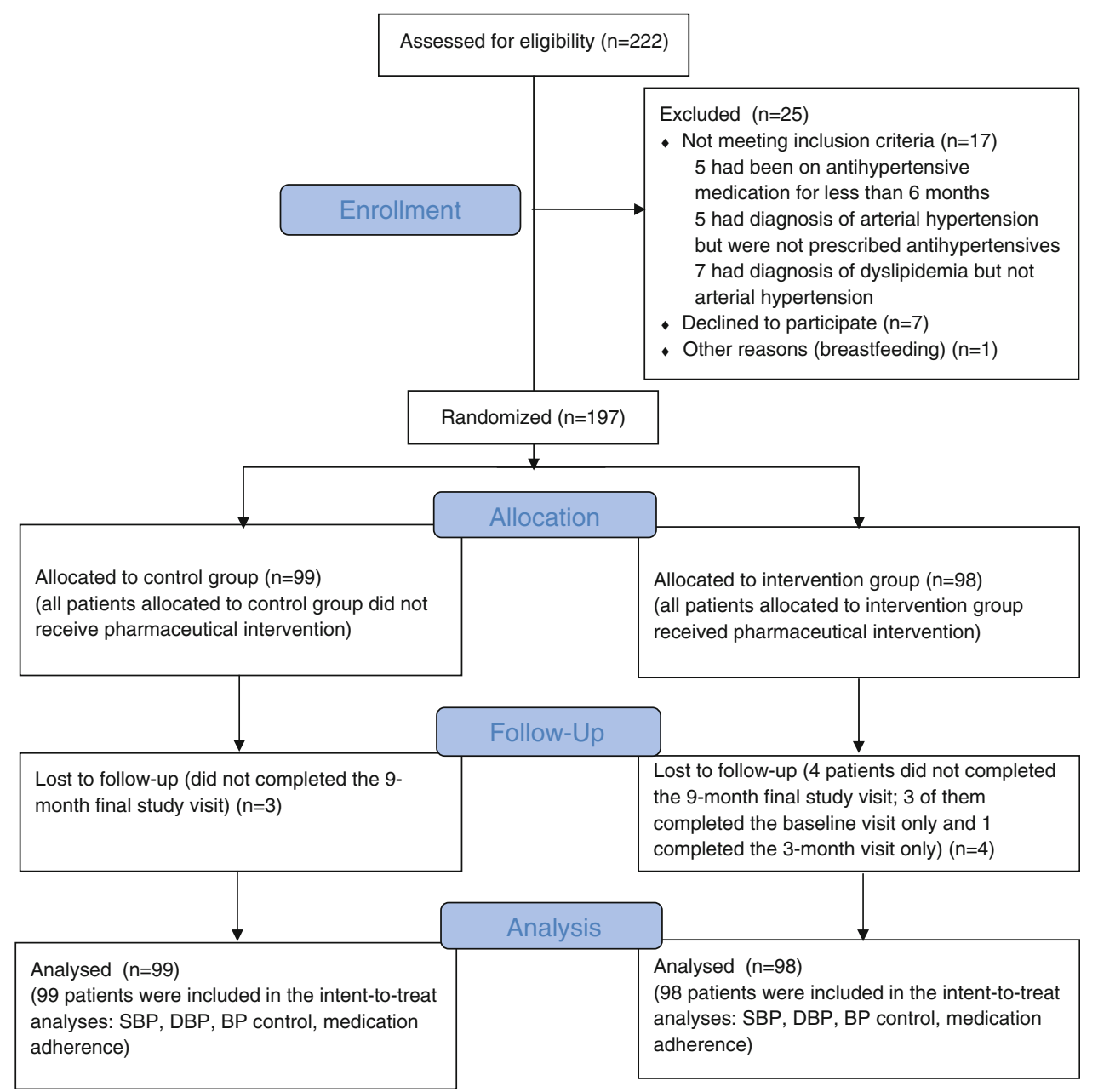

controlled $(P=0.480)$. At the end of the study, BP was controlled among significantly more patients in the IG $(66.0 \%)$ than in the CG $(41.7 \%)(P=0.0008)$, with an odds ratio of 2.7 (95\% CI, 1.5-4.9) (Table 3).

The SBP was reduced by $0.8 \mathrm{mmHg}$ in the $\mathrm{CG}$ and $7.6 \mathrm{mmHg}$ in the IG $(P=0.005$ for between-group SBP comparison). The DBP was reduced by $1.1 \mathrm{mmHg}$ in the $\mathrm{CG}$ and $3.0 \mathrm{mmHg}$ in the IG $(P=0.016$ for betweengroup DBP comparison) (Table 3 ).

A sensitivity analysis to determine the robustness of our findings in the presence of informative dropout was performed. The analysis was repeated under the most pessimistic scenario in which all 4 dropouts in the IG had uncontrolled BP and all 3 dropouts in the CG had controlled BP. In this situation, the respective BP control rates would be 63.3 and $43.4 \%$ (odds ratio of 2.2; $95 \%$ CI 1.3-4.0; $P=0.005)$. Similarly, if we consider the last available clinic BP extracted in all 7 dropouts, SBP was reduced by $0.9 \mathrm{mmHg}$ in the $\mathrm{CG}$ and $7.4 \mathrm{mmHg}$ in the IG ( $P=0.006$ for between-group SBP comparison). The DBP was reduced by $1.0 \mathrm{mmHg}$ in the $\mathrm{CG}$ and $2.7 \mathrm{mmHg}$ in the IG ( $P=0.020$ for between-group DBP comparison) (Table 3).

The intervention pharmacist made 118 recommendations about antihypertensive therapy, of which $90(76.3 \%)$ were accepted by physicians. These recommendations included maintaining current antihypertensive medication (54.2\%), introduction of additional medication $(25.4 \%)$, dosage increase of existing medication (13.5\%), cessation of current medication (5.9\%) and dosage decrease of existing medication $(0.8 \%)$. Despite these recommendations, the mean of overall changes in antihypertensive medication did not differ in IG and CG (0.65 vs. 0.72 changes per subject in the IG and $\mathrm{CG}$, respectively, $P=0.693$ ), neither did the number of new antihypertensive medications ( 0.34 vs. $0.37, P=0.768)$ or the number of discontinued antihypertensive medications (0.20 vs. $0.19, P=0.879)$. Likewise, the mean $\pm \mathrm{SD}$ number of antihypertensive medications was not different between the IG $(2.8 \pm 1.3$ medications $)$ and the CG (2.7 \pm 1.4 medications $)$ at the end of the study $(P=0.682)$. Similarly, the antihypertensive medications prescribed did not 
Table 1 Patients demographics and clinical characteristics at baseline (n = 197)

\begin{tabular}{|c|c|c|c|}
\hline Demographic/clinical & $\begin{array}{l}\text { Control group } \\
(\mathrm{n}=99)\end{array}$ & $\begin{array}{l}\text { Intervention group } \\
(\mathrm{n}=98)\end{array}$ & $P$ value \\
\hline Gender, n (\%) & & & 0.171 \\
\hline Male & $35(35.4)$ & $44(44.9)$ & \\
\hline Female & $64(64.4)$ & $54(55.1)$ & \\
\hline Age, mean $(\mathrm{SD})^{\mathrm{a}}$ & $60.7(11.8)$ & $58.3(11.6)$ & 0.155 \\
\hline Body mass index $\left(\mathrm{kg} / \mathrm{m}^{2}\right)$, mean (SD) & $29.0(4.7)$ & $29.8(4.9)$ & 0.261 \\
\hline Married, n (\%) & $85(85.9)$ & $75(76.5)$ & 0.094 \\
\hline Education, n (\%) & & & 0.991 \\
\hline Illiterate & $5(5.1)$ & $5(5.1)$ & \\
\hline Elementary schooling & $79(79.8)$ & $77(78.6)$ & \\
\hline High schooling & $10(10.1)$ & $10(10.2)$ & \\
\hline University education & $5(5.1)$ & $6(6.1)$ & \\
\hline Current smoker, n (\%) & $8(8.1)$ & $9(9.2)$ & 0.777 \\
\hline \multicolumn{4}{|l|}{ Comorbid conditions, n (\%) } \\
\hline Cerebrovascular disease & $15(15.2)$ & $11(11.2)$ & 0.417 \\
\hline Chronic kidney disease & $6(6.1)$ & $5(5.1)$ & 0.764 \\
\hline Diabetes & $18(18.2)$ & $18(18.4)$ & 1.000 \\
\hline Heart failure & $1(1.0)$ & $0(0.0)$ & 1.000 \\
\hline Ischemic heart disease & $4(4.0)$ & $1(1.0)$ & 0.369 \\
\hline Myocardial infarction & $2(2.0)$ & $1(1.0)$ & 1.000 \\
\hline Left ventricular hypertrophy & $2(2.0)$ & $3(3.1)$ & 0.683 \\
\hline Dyslipidemia & $70(70.7)$ & $78(79.6)$ & 0.149 \\
\hline Metabolic syndrome & $3(3.0)$ & $1(1.0)$ & 0.621 \\
\hline Obesity (body mass index $\geq 30$ ) & $43(43.4)$ & $40(40.8)$ & 0.708 \\
\hline Advanced age ( $\geq 65$ years), $\mathrm{n}(\%)$ & $34(34.3)$ & $30(30.6)$ & 0.578 \\
\hline None of the above, n (\%) & $11(11.1)$ & $8(8.2)$ & 0.484 \\
\hline $\begin{array}{l}\text { Number of antihypertensive drugs per } \\
\text { patient, mean (SD) }\end{array}$ & $2.6(1.4)$ & $2.7(1.3)$ & 0.437 \\
\hline $\begin{array}{l}\text { Number of years in antihypertensive drug } \\
\text { treatment, mean (SD) }\end{array}$ & $9.1(6.6)$ & $8.6(6.4)$ & 0.572 \\
\hline
\end{tabular}

a $S D$ standard deviation

Both differences remained significant when data were assessed by ITT analysis (Table 3).

\section{Discussion}

The pharmacist intervention program developed for this 9month study resulted in significant reduction of SBP and DBP and in an increase in the proportion of patients with controlled BP according to JNC-7 guidelines. The odds of achieving BP target in the IG were 2.7 times higher than the CG (95\% CI, 1.5-4.9; $P<0.001)$. These differences remained significant when data were assessed by ITT analysis. Among hypertensive patients aged 60-69 years, the additional $6.8 \mathrm{mmHg}$ reduction in SBP observed in intervention arm would be expected to yield a $22 \%$ reduction in stroke mortality and a $17 \%$ reduction in mortality from ischemic heart disease [24]. Thus, inclusion 
Table 2 Antihypertensive medication prescribed to hypertensive patients at baseline and at the end of the study

\begin{tabular}{|c|c|c|c|}
\hline Antihypertensive drug class & $\begin{array}{l}\text { Control group (Baseline, } \\
n=99 \text { ) (End of study, } \\
n=99)^{\mathrm{a}}\end{array}$ & $\begin{array}{l}\text { Intervention group (Baseline, } \\
\mathrm{n}=98)(\text { End of study, } \\
\mathrm{n}=98)^{\mathrm{a}}\end{array}$ & $P$ value \\
\hline \multirow[t]{2}{*}{ Loop diuretics $(\%)$} & 18.2 & 11.2 & 0.168 \\
\hline & 18.2 & 12.2 & 0.247 \\
\hline \multirow[t]{2}{*}{ Thiazide diuretics $(\%)$} & 59.6 & 64.3 & 0.498 \\
\hline & 63.6 & 67.3 & 0.584 \\
\hline \multirow[t]{2}{*}{ Potassium-sparing diuretic (\%) } & 6.1 & 3.1 & 0.498 \\
\hline & 6.1 & 4.1 & 0.747 \\
\hline \multirow[t]{2}{*}{ Renin inhibitor (\%) } & 3.0 & 2.0 & 1.000 \\
\hline & 3.0 & 4.1 & 0.721 \\
\hline \multirow[t]{2}{*}{ ACE inhibitors $(\%)$} & 32.3 & 33.7 & 0.841 \\
\hline & 32.3 & 35.7 & 0.617 \\
\hline \multirow[t]{2}{*}{ Angiotensin II receptor antagonists (\%) } & 47.5 & 64.3 & 0.018 \\
\hline & 52.5 & 64.3 & 0.094 \\
\hline \multirow[t]{2}{*}{ Calcium channel blockers $(\%)$} & 35.4 & 45.9 & 0.131 \\
\hline & 42.4 & 44.9 & 0.729 \\
\hline \multirow[t]{2}{*}{ Beta blockers $(\%)$} & 47.5 & 41.8 & 0.427 \\
\hline & 47.5 & 42.9 & 0.517 \\
\hline \multirow[t]{2}{*}{ Central alpha-2 agonists (\%) } & 8.1 & 7.1 & 0.806 \\
\hline & 8.1 & 6.1 & 0.590 \\
\hline
\end{tabular}

Bold means that there is a statistically significant difference $(P$ value $<0.05)$

${ }^{a}$ Includes last medication prescribed before the final study visit (including to dropouts) may be attributed to an intensification of antihypertensive medication and some pharmacist interventions led to a significant improvement in BP control by this mechanism, i.e., overcoming clinical inertia [23, 29, 30]. However, most studies that reported a statistically significant increase in medication adherence also reported a statistically significant improvement in treatment outcomes, which reveals that medication adherence is a key factor (although not the only one) to achieve BP control [12, 13, 15, 31-34]. When baseline medication adherence is high $(>75 \%)$, pharmacist interventions are not likely to find a statistically significant improvement in this outcome [14, 23, 28, 30]. In the current study, the low baseline medication adherence $(<50 \%)$ made it feasible for pharmaceutical intervention to have a positive effect in this outcome and hence in treatment outcomes. Increase in medication adherence obtained could be attributed to the hypertension and drug education given to patients. Lack of knowledge about BP targets, hypertension complications and the benefits of antihypertensive medication have been recognized as a barrier to adherence [35-37].

Several limitations of this study must be mentioned. First, although RCTs provide the highest internal validity by controlling confounding bias, their use is limited by contaminating the $\mathrm{CG}$ by contact with the intervention program. In the present study, randomisation at the patient level, as opposed to pharmacist or physician, may have resulted in contamination bias. Several patients in the $\mathrm{CG}$ asked the pharmacist about their goal BP targets and 
Table 3 Clinic BP figures, BP control, antihypertensive medication adherence and knowledge about hypertension (baseline, end of the study and ITT analysis)

\begin{tabular}{|c|c|c|c|}
\hline Variable & Control group & Intervention group & $P$ value \\
\hline Baseline & $(\mathrm{n}=99)$ & $(\mathrm{n}=98)$ & \\
\hline Baseline SBP, mean (SD), mmHg & $141.9(16.8)$ & $141.6(16.3)$ & 0.873 \\
\hline Baseline DBP, mean (SD), mmHg & $86.4(11.7)$ & $85.2(10.2)$ & 0.438 \\
\hline Baseline BP control, n (\%) & $35(35.4)$ & $30(30.6)$ & 0.480 \\
\hline Baseline stage $1 \mathrm{HT}, \mathrm{n}(\%)$ & $39(39.4)$ & $43(43.9)$ & 0.522 \\
\hline Baseline stage $2 \mathrm{HT}, \mathrm{n}(\%)$ & $22(22.2)$ & $20(20.4)$ & 0.752 \\
\hline Baseline low medication adherence, n (\%) & $50(50.5)$ & $52(53.1)$ & 0.718 \\
\hline Knowledge of target BP values, n (\%) & $59(59.6)$ & $58(59.2)$ & 1.000 \\
\hline Knowledge of hypertension risks, n (\%) & $54(54.5)$ & $54(55.1)$ & 0.920 \\
\hline End of the study & $(\mathrm{n}=96)$ & $(n=94)$ & \\
\hline End SBP, mean (SD), mmHg & $141.1(18.0)$ & $134.0(16.0)$ & 0.005 \\
\hline End DBP, mean (SD), mmHg & $85.3(8.9)$ & $82.2(8.7)$ & 0.016 \\
\hline End BP control, n (\%) & $40(41.7)$ & $62(66.0)$ & 0.0008 \\
\hline End low medication adherence, n (\%) & $42(43.8)$ & $21(22.3)$ & 0.0017 \\
\hline Knowledge of target BP values, $\mathrm{n}(\%)$ & $61(63.5)$ & 77 (81.9) & 0.005 \\
\hline Knowledge of hypertension risks, n (\%) & $63(65.6)$ & $79(84.0)$ & 0.003 \\
\hline ITT analysis & $(\mathrm{n}=99)$ & $(\mathrm{n}=98)$ & \\
\hline ITT SBP (includes last value carried forward), mean (SD), $\mathrm{mmHg}$ & $141.0(18.0)$ & $134.2(16.0)$ & 0.006 \\
\hline ITT DBP (includes last value carried forward), mean (SD), $\mathrm{mmHg}$ & $85.4(9.1)$ & $82.5(8.6)$ & 0.020 \\
\hline ITT BP control ${ }^{\mathrm{a}}, \mathrm{n}(\%)$ & $43(43.4)$ & $62(63.3)$ & 0.005 \\
\hline ITT low medication adherence ${ }^{\mathrm{b}}, \mathrm{n}(\%)$ & $42(42.4)$ & $25(25.5)$ & 0.012 \\
\hline ITT knowledge of target BP values ${ }^{\mathrm{b}}, \mathrm{n}(\%)$ & 64 (64.6) & $77(78.6)$ & $\mathbf{0 . 0 3 0}$ \\
\hline ITT knowledge of hypertension risks ${ }^{\mathrm{b}}, \mathrm{n}(\%)$ & $66(66.7)$ & 79 (80.6) & 0.026 \\
\hline
\end{tabular}

Bold means that there is a statistically significant difference $(P$ value $<0.05)$

a Admitting that all patients from control group lost to follow-up had their BP controlled at the end of the 9-month study and that all patients from intervention group lost to follow-up had their BP uncontrolled at the end of the 9-month study

b Admitting that all patients from control group lost to follow-up were adherent and knew target BP values and hypertension risks at the end of the 9-month study and that all patients from intervention group lost to follow-up were no adherent and did not known target BP values and hypertension risks at the end of the 9-month study

$B P$ blood pressure, $D B P$ diastolic blood pressure, $H T$ hypertension, $I T T$ intention-to-treat, $S B P$ systolic blood pressure, $S D$ standard deviation

about the possible serious consequences of high BP at the beginning of the study, and, further, physicians in the study cared for patients in both groups. Although contamination was considered during the study design, researchers recognized that it would conservatively represent bias toward the null hypothesis. Second, the evaluation of BP control was based on the measurements performed in two single clinic appointments (baseline and after a 9-month followup period). These BP measurements may or may not be representative of the adequacy of BP control in hypertensive patients, even though they were performed by blinded nurses, which contributes to the validity of observed effects. Third, medication adherence was measured by the research (not blinded) pharmacist, which is potentially biased in situations where the patient does not respond with determination to the questionnaire. Finally, the intervention was short, lasting only 9 months. Future research should be of a longer duration to determine if the effect of pharmacist management of hypertension is sustainable.

\section{Conclusion}

Pharmacist intervention can modify factors affecting adherence, improve adherence and reduce BP levels in patients treated with antihypertensive agents. This study suggests that one effective method of improving BP control is for pharmacists to recognize inadequate hypertension knowledge and medication adherence and develop strategies that enlist the patient as a participant in the management of his/her health. Thereby, this report also reinforces the pharmacists' role in improving the health care system, leading to superior hypertensive patient outcomes. 
Funding This work was supported by Fundação para a Ciência e a Tecnologia (SFRH/BD/36756/2007) through a fellowship grant attributed to MM

\section{Conflict of interest None.}

Open Access This article is distributed under the terms of the Creative Commons Attribution Noncommercial License which permits any noncommercial use, distribution, and reproduction in any medium, provided the original author(s) and source are credited.

\section{References}

1. De Macedo ME, Lima MJ, Silva AO, Alcantara P, Ramalhinho V, Carmona J. Prevalence, awareness, treatment and control of hypertension in Portugal. The PAP study. Rev Port Cardiol. 2007;26(1):21-39.

2. Chobanian AV, Bakris GL, Black HR, Cushman WC, Green LA, Izzo JL Jr, et al. Seventh report of the joint national committee on prevention, detection, evaluation, and treatment of high blood pressure. Hypertension. 2003;42(6):1206-52.

3. Collins R, Peto R, MacMahon S, Hebert P, Fiebach NH, Eberlein $\mathrm{KA}$, et al. Blood pressure, stroke, and coronary heart disease. Part 2, Short-term reductions in blood pressure: overview of randomised drug trials in their epidemiological context. Lancet. 1990;335(8693):827-38.

4. Godley P, Pham H, Rohack J, Woodward B, Yokoyama K, Maue SK. Opportunities for improving the quality of hypertension care in a managed care setting. Am J Health Syst Pharm. 2001;58(18):1728-33.

5. Whitworth JA. 2003 World Health Organization (WHO)/International Society of Hypertension (ISH) statement on management of hypertension. J Hypertens. 2003;21(11):1983-92.

6. Schroeder K, Fahey T, Ebrahim S. How can we improve adherence to blood pressure-lowering medication in ambulatory care? Systematic review of randomized controlled trials. Arch Intern Med. 2004;164(7):722-32.

7. Munger MA, Van Tassell BW, LaFleur J. Medication nonadherence: an unrecognized cardiovascular risk factor. MedGenMed. 2007;9(3):58.

8. Dowell J, Jones A, Snadden D. Exploring medication use to seek concordance with 'non-adherent' patients: a qualitative study. $\mathrm{Br}$ J Gen Pract. 2002;52(474):24-32.

9. Ebrahim S. Detection, adherence and control of hypertension for the prevention of stroke: a systematic review. Health Technol Assess (Winch Eng). 1998;2(11):i-iv,1-78.

10. Psaty BM, Koepsell TD, Yanez ND, Smith NL, Manolio TA, Heckbert SR, et al. Temporal patterns of antihypertensive medication use among older adults, 1989 through 1992. An effect of the major clinical trials on clinical practice? JAMA. 1995; 273(18):1436-8.

11. Caro JJ, Speckman JL, Salas M, Raggio G, Jackson JD. Effect of initial drug choice on persistence with antihypertensive therapy: the importance of actual practice data. CMAJ. 1999;160(1):41-6.

12. Aguwa CN, Ukwe CV, Ekwunife OI. Effect of pharmaceutical care programme on blood pressure and quality of life in a Nigerian pharmacy. Pharm World Sci. 2008;30(1):107-10.

13. Blenkinsopp A. Extended adherence support by community pharmacists for patients with hypertension: a randomised controlled trial. Int J Pharm Pract. 2000;8:165-75.

14. Chabot I, Moisan J, Gregoire JP, Milot A. Pharmacist intervention program for control of hypertension. Ann Pharmacother. 2003;37(9):1186-93.
15. Sookaneknun P, Richards RM, Sanguansermsri J, Teerasut C. Pharmacist involvement in primary care improves hypertensive patient clinical outcomes. Ann Pharmacother. 2004;38(12): 2023-8.

16. Zillich AJ, Sutherland JM, Kumbera PA, Carter BL. Hypertension outcomes through blood pressure monitoring and evaluation by pharmacists (HOME study). J Gen Intern Med. 2005; 20(12):1091-6.

17. Polonia J, Ramalhinho V, Martins L, Saavedra J. Portuguese society of cardiology recomendations, assessment and treatment of hypertension. Rev Port Cardiol. 2006;25(6):649-60.

18. El Assaad MA, Topouchian JA, Asmar RG. Evaluation of two devices for self-measurement of blood pressure according to the international protocol: the Omron M5-I and the Omron 705IT. Blood Press Monit. 2003;8(3):127-33.

19. Shea S, Misra D, Ehrlich MH, Field L, Francis CK. Correlates of nonadherence to hypertension treatment in an inner-city minority population. Am J Public Health. 1992;82(12):1607-12.

20. Shea S, Misra D, Ehrlich MH, Field L, Francis CK. Predisposing factors for severe, uncontrolled hypertension in an inner-city minority population. N Engl J Med. 1992;327(11):776-81.

21. Morisky DE, Green LW, Levine DM. Concurrent and predictive validity of a self-reported measure of medication adherence. Med Care. 1986;24(1):67-74.

22. Morisky DE, Levine DM, Green LW, Shapiro S, Russell RP, Smith CR. Five-year blood pressure control and mortality following health education for hypertensive patients. Am J Public Health. 1983;73(2):153-62.

23. Carter BL, Ardery G, Dawson JD, James PA, Bergus GR, Doucette WR, et al. Physician and pharmacist collaboration to improve blood pressure control. Arch Intern Med. 2009;169(21): 1996-2002.

24. Lewington S, Clarke R, Qizilbash N, Peto R, Collins R. Agespecific relevance of usual blood pressure to vascular mortality: a meta-analysis of individual data for one million adults in 61 prospective studies. Lancet. 2002;360(9349):1903-13.

25. Machado M, Bajcar J, Guzzo GC, Einarson TR. Sensitivity of patient outcomes to pharmacist interventions. Part II: systematic review and meta-analysis in hypertension management. Ann Pharmacother. 2007;41(11):1770-81.

26. Carter BL, Rogers M, Daly J, Zheng S, James PA. The potency of team-based care interventions for hypertension: a meta-analysis. Arch Intern Med. 2009;169(19):1748-55.

27. Mehos BM, Saseen JJ, MacLaughlin EJ. Effect of pharmacist intervention and initiation of home blood pressure monitoring in patients with uncontrolled hypertension. Pharmacotherapy. 2000; 20(11):1384-9.

28. Roumie CL, Elasy TA, Greevy R, Griffin MR, Liu X, Stone WJ, et al. Improving blood pressure control through provider education, provider alerts, and patient education: a cluster randomized trial. Ann Intern Med. 2006;145(3):165-75.

29. Vivian EM. Improving blood pressure control in a pharmacistmanaged hypertension clinic. Pharmacotherapy. 2002;22(12): $1533-40$.

30. Carter BL, Bergus GR, Dawson JD, Farris KB, Doucette WR, Chrischilles EA, et al. A cluster randomized trial to evaluate physician/pharmacist collaboration to improve blood pressure control. J Clin Hypertens (Greenwich). 2008;10(4):260-71.

31. Brouker ME, Gallagher K, Larrat EP, Dufresne RL. Patient compliance and blood pressure control on a nuclear-powered aircraft carrier: impact of a pharmacy officer. Mil Med. 2000; 165(2):106-10

32. de Souza WA, Yugar-Toledo JC, Bergsten-Mendes G, Sabha M, Moreno H Jr. Effect of pharmaceutical care on blood pressure control and health-related quality of life in patients with resistant hypertension. Am J Health Syst Pharm. 2007;64(18):1955-61. 
33. Lai LL. Community pharmacy-based hypertension disease-management program in a Latino/Hispanic-American population. Consult Pharm. 2007;22(5):411-6.

34. Lee JK, Grace KA, Taylor AJ. Effect of a pharmacy care program on medication adherence and persistence, blood pressure, and low-density lipoprotein cholesterol: a randomized controlled trial. JAMA. 2006;296(21):2563-71.

35. Whelton PK, He J, Appel LJ, Cutler JA, Havas S, Kotchen TA, et al. Primary prevention of hypertension: clinical and public health advisory from the national high blood pressure education program. JAMA. 2002;288(15):1882-8.

36. Oliveria SA, Chen RS, McCarthy BD, Davis CC, Hill MN. Hypertension knowledge, awareness, and attitudes in a hypertensive population. J Gen Intern Med. 2005;20(3):219-25.

37. Ragot S, Sosner P, Bouche G, Guillemain J, Herpin D. Appraisal of the knowledge of hypertensive patients and assessment of the role of the pharmacists in the management of hypertension: results of a regional survey. J Hum Hypertens. 2005;19(7):577-84. 